\title{
Gender Discrimination in Disabled Adolescents: An Analysis of Psychological Adjustment in a Cosmopolitan City in Pakistan
}

\author{
Kiran Bashir Ahmad*, Zainab F. Zadeh \\ Institute of Professional Psychology, Bahria University, Pakistan \\ *Corresponding Author: kiranba@live.com
}

Copyright (C) 2014 Horizon Research Publishing All rights reserved.

\begin{abstract}
The research focuses on gender discrimination in the psychological adjustment of adolescents with disabilities growing up in Pakistan. In the light of the literature review, it was assumed that disabled male adolescents would show greater levels of psychological adjustment as compared to disabled female adolescents. The sample population consisted of a total of 100 disabled adolescents experiencing visual, auditory or physical disabilities. The hypothesis was strongly supported by the results $[\mathrm{t}(98)=2.576, \quad \mathrm{p}<.05(.012)]$ as disabled male adolescents were found to rank higher on levels of psychological adjustment as compared to disabled female adolescents. Gender discrimination hence emerges as a significant issue for disabled adolescents. The research carries implications for clinicians and educationists alike, as well as policymakers; especially with regard to the development of male and female adolescents in the existing cultural milieu in Pakistan.
\end{abstract}

Keywords Adolescence, Girls, Gender, Adjustment, Disability, Blind, Deaf, Physically Disabled

\section{Introduction}

Psychological Adjustment is the ability to have an accurate perception of reality, the ability to cope with stress and anxiety, a positive self image, the ability to express the full range of emotions and to have good interpersonal skills (Haber \& Runyon,1984).

The interplay of gender with psychological adjustment is best understood through the lens of various socio-cultural factors that often come in play when viewing the maladjustment - adjustment continuum. These can lead to issues increasing in level from gender differentiation at the very least to gender discrimination. Gender disparities may play a significant role in the Pakistani society and may affect self esteem as well as the level of social support given by primary and secondary caregivers, the community and the society at large, to the individual. In general, emotional maltreatment arising out of a lack of social support shown by emotional neglect including psychological unavailability and emotional abuse such as verbal criticism and hostility are linked to increased aggression and social withdrawal in middle childhood and lowered socio-emotional competence in early adolescence. This is more significant for boys than for girls. (Shafer, Yates \& Egeland, 2009).

According to Mirza (1994), in a normal sample of post graduate students, females were seen to have unhealthier perceptions of family dynamics and were consequently found to be more maladjusted than their male counterparts. The reasons for this can be several but the study suggests the factor of oppression of females by the male dominated society as one of the main factors in the indecision they face in life.

Disability can be broadly categorized in two dimensions for the purpose of this study - sensory or physical disability. This is the difficulty or loss of ability of an individual to meet socially defined behavioural expectations, and consequently regarded by society as different in appearance or behaviour (Turner \& McLean, 1989; World Health Organization, 1980Itteyerah \& Kumar, 2007). Schillmeier (2008), on the other hand describes inclusive differences in disability as the practice constituting disabling practices in everyday life brought about by the relationship between the sensory experience and the material environment - a perspective that he argues is under-researched and still highly neglected by both social science as well as disability studies. It is relevant here to understand the relationship some culturally disabling notions may have on a factor such as gender.

Literature reviews show a strong tilt towards gender inequality in Pakistan especially in the case of the disabled. Ayubia (1986) while studying a sample of 200 male and female children focussed on nine different factors that play an important role in the social adjustment of those with a sensory or physical disability. Apart from significant male female differences in which females were found to be less socially adjusted than males, the biggest factor was that of having a 'dependency upon others' along with a 'doubtful 
future'. Other important factors were the 'disability to play', 'organic inferiority' and 'sense of insecurity'.

In the Pakistani and Indian cultures, boys are seen as the natural breadwinners of the family and consequently it has been observed that much more care is taken of their needs, as in the case of the blind (Mehta, 1984), than those of girls. In many tribal cultures in Pakistan, investing in a girl's education or providing vocational guidance is considered a waste, however in certain cases the situation reverses. It is interesting to note that as a disabled girl is hardly ever expected to get married, she is taught household chores or sewing to pass her time in her father or brother's house and earn her living in this manner to lessen the burden of those with whom she is destined to live. In case she does get married, she is hardly ever allowed to forget the fact that she is disabled. The problems increase in cases of facial disfigurement (Das \& Addlakha, 2001, 2007). Even in old age, there is no respite for the disabled populace claims Cohen (1998) in his account of the Indian geriatric population.

While in issues related to self confidence and self image, no significant gender differences have been discovered in the adolescents with low vision in the $12-17$ years age group (Khan, 2008), Kazmi (2001) in the case of blind adolescent girls, reports a higher average score on subjective well being as compared to blind adolescent boys indicating better adjustment for the girls.

Among the handicapped population in Pakistan (Ayubia, 1986), whether they are blind, deaf and dumb or physically disabled, better social adjustment of boys is reported as compared to girls. Boys on the other hand have been found to dislike 'sympathetic attitude of other people' which is again significantly different from that of girls and contributes to their lack of adjustment where found. This along with heightened sensitivity has been found to correlate with an inferiority complex in girls, who also experience a 'sense of uselessness' and 'lack of confidence' which is significantly different from that of boys and affects their self esteem (Ayubia, 1986 \& Ahmed, 2003).

In the generally conservative cultural context of Pakistan, the play time and leisure activities of blind female students are limited to indoor singing and a local dance luddi. Activities that may bring them in contact with males outside the classroom are discouraged, while making them focus more on studies to supposedly fill in the gap (Bano \& Hameed, 2011).

General recreation aside, regular physical education classes in schools and sports activities also suffer. The physical education of visually challenged girls remains substandard in Pakistan. Researchers Bano and Hameed (2011) have severely criticised the quality of teachers as well as the equipment for physical education provided in special schools. Their work shows a marked disparity between these girls as compared to the visually challenged boys and the normal population. According to them, as a result, the physical posture of the girls is affected and even the curriculum along with the sports opportunities provided lag behind severely in terms of international standards.

It is important to understand the nature of Pakistani society that may lead towards gender discrimination. According to Hofstede's five dimensional model (1991, 2001), Pakistan scores 50 on the dimension of Masculinity/Femininity which translates into it being a Masculine society. Such a society is driven by competition, achievement and success - a pattern that starts in school. However there is gender differentiation as males are expected to be assertive as the future heads of the family and females are not expected to show assertiveness. Fathers being the breadwinners are expected to decide the family size and deal with hard facts in the family and their work would take precedence over family issues. Mothers are expected to show more maternal attributes, acting as the buffer for the feelings of their children and others in the family and for encouraging girls to cry out their feelings dissuading boys from doing the same. This may be one of the causes of additional stress in the long run for the females. If the burden of a disability is added to this, coping styles may be compromised, leading towards reduced adjustment. As the Pakistani society is a collectivist culture the amount of support received and considered to be supportive at a subjective level, is observed to be of importance in determining the psychological adjustment of the disabled person. The scenario seems to be worse for the self esteem, social support and the adjustment of females (Nancoo, 2011).

The analysis of the literature suggests the hypothesis that disabled male adolescents will show greater levels of psychological adjustment as compared to disabled female adolescents.

\section{Methods}

\subsection{Participants}

A total of 100 male and female disabled adolescents between the ages of twelve years to twenty years (with blindness, hearing impairment and physical disabilities orthopaedic) were included in the sample. There were a total of 40 blind adolescents with full blindness or partial blindness at a severe level, 34 deaf adolescents with full deafness or partial deafness at a severe level, 26 physically disabled adolescents with orthopaedic disabilities. They were divided into two groups later based on gender for statistical analysis (47 males and 53 females). Various vocational training centres, special schools for the blind and the hearing impaired and occupational settings in Karachi were explored to conduct detailed interviews and build adequate rapport in order to use psychological tests with disabled adolescents.

Adolescents with known and documented cognitive and intellectual deficits in thinking, judgement and perception, or those diagnosed with Autism, Mental Retardation, Attention Deficit Hyperactivity Disorder and/ or Cerebral Palsy, based on teacher or caregiver reports were excluded from the study 
even if they had an additional sensory or physical disability. This was done to ensure the attentive and cognizant responses of the participants of the study who were expected to fill out the given self report questionnaires on their own or with the help of the researcher. Keeping in view the literature review and the issues surrounding the area of multiple disabilities with mental retardation (Thomas \& Singh, 2006), this was also ruled out in the case of the participants. In addition, adolescent beggars and / or street children with disabilities are not included in the sample in order to control for extraneous variables that may affect the given psychosocial variables.

\subsection{Procedure}

The study took place in five phases including the first phase of test selection, the second phase of the development of the demographic information questionnaire, the third phase of the identification of the sample using purposive sampling, the fourth phase of test administration and the fifth interlinked phase of the compilation of the data after which statistical analysis procedures were carried out. It was decided in the first phase that an indigenous scale in the Urdu language would be used to measure adjustment levels in order to maximize the reach towards the local population. The selection of the Psychological Adjustment Scale (PAS) in Urdu by Fizza Sabir (1999), an M.Phil. candidate at the National Institute of Psychology, Islamabad, was therefore made on the basis of its usability with the student population. SPSS Version 16 was used to compute the results and analyse the data.

The identification of adolescents with disabilities was kept at first priority as this could prove to be a sample that was hard to find. An initial list of schools, hospitals and organizations catering to the disabled population, was compiled and these places were approached in the same order. It is important to note here that several problems were encountered in the initial review of the schools, hospitals and organizations that were approached. This restricted the researcher to approach only those that would allow a follow up to fill in missing items in the forms or to those that allowed direct contact.

It was found that many school authorities do not allow researchers to approach their students directly. In some cases the researchers are not even allowed to enter the premises and can only meet the school authorities, submit the forms and come back a second time to retrieve the filled forms. Eventually due to the large number of missing items and incorrectly filled responses, forms from such schools were excluded from the list.

It was decided that the research would be conducted using an interview format. In this manner more could be gleaned from the participants and later added in the discussion of results. On an average each interview took 1 hour per participant and observations were noted informally regarding their emotional expressivity and additional statements that were triggered by their responses to the questionnaire. The respondents' approach was seen as visibly different with regard to both genders during data collection and this is important information, considering the type and quality of the results obtained. Most disabled boys as compared to disabled girls wanted the researcher to communicate the results to their families and where contact numbers were given, the results were provided.

\subsection{Measures}

\subsubsection{Demographic information form}

This form has been used to collect data about psychosocial variables that could influence the results. It includes information about the name or abbreviation in cases of persons who do not wish to disclose their identity. Names were taken down in order to build rapport as the research was carried out using an interview format. Other variable noted included information about gender, age, education (grade level currently enrolled in and last grade level completed), marital status, birth order, and number of siblings, family structure (nuclear or joint), occupation, socio-economic status and nature of sensory or physical disability including type, duration and cause.

\subsubsection{Psychological Adjustment Scale (PAS), (Sabir, 1999)}

This 27 item scale measures psychological adjustment according to the theoretical framework of Haber and Runyon (1984) that describes good psychological adjustment along five subscales A: an accurate perception of reality (items 3, 6, 23 and 27), B: ability to cope with stress and anxiety (items 2 , 4, 7, 8, 25 and 26), C: a positive self image $(5,10,13,15,16$, 17, 21), D: ability to express the full range of emotions (items 1, 11, 14, 18, 22 and 24), and E: good interpersonal relationships (items $9,12,19$ and 20). It has no age limitations and according to the author, it can be used with youngsters, adolescents or even old people. It has been standardized with University students for which population the scale has high reliability at 0.83 while the split half reliability is 0.85 .

It has a 5 point rating scale with response categories for Strongly Agree (scored 5), Agree (scored 4), Neither Agree Nor Disagree (scored 3), Disagree (scored 2) and Strongly disagree (scored 1). Items 1, 4, 5, 7, 11, 14, 18, 19, 22, 23, 24 , and 25 are negatively phrased. A total score is computed with a cut off point of 81 . Students scoring above 81 are considered to have better psychological adjustment and those scoring below 81 are considered to have poor psychological adjustment.

\section{Results}

The results of the research show a highly significant difference at the $95 \%$ confidence interval in the mean psychological adjustment scores for disabled male adolescents $(p<.05)$.

Figure 1 shows the gender distribution of males and 
females in the sample population. It can be seen that the male - female ratio is roughly equal across all groups.

Figure 2 is a clustered box plot depicting the values of psychological adjustment in blind males and females, deaf males and females, physically disabled males and females along with the nondisabled males and females presented here as an adjunct for comparative understanding. The median score values are denoted by the horizontal line. The graph visibly shows that the PAS scores showing the adjustment values of males are higher than the PAS scores showing the adjustment values of females. This disparity can be seen more in the case of blind and deaf adolescents as compared to physically disabled adolescents.

The results support the idea that female disabled adolescents are more likely to experience issues related to psychological adjustment in various settings as compared to male disabled adolescents who may show better psychological adjustment.

Table 1. Gender Distribution of the Disabled Adolescents Sample Data $(\mathrm{N}=100)$

\begin{tabular}{|c|c|c|c|}
\hline & Blind & Deaf & Physically disabled \\
\hline Gender distribution & $(n=40)$ & $(n=34)$ & $(n=26)$ \\
\hline Male & 20 & 15 & 12 \\
\hline Female & 20 & 19 & 14 \\
\hline
\end{tabular}

Table 2. T-test between Disabled Male Adolescents and Disabled Female Adolescents for the Variable of Psychological Adjustment (N=100)

\begin{tabular}{|c|c|c|c|c|c|c|c|c|}
\hline Variable & Groups & $\mathrm{n}$ & $\mathrm{M}$ & $\mathrm{SD}$ & $\mathrm{SEM}$ & $\mathrm{df}$ & Sig. & $\mathrm{t}$ \\
\hline $\begin{array}{c}\text { Psychological } \\
\text { Adjustment }\end{array}$ & Male & 47 & 157.87 & 17.783 & 2.594 & & & \\
\cline { 2 - 9 } & Female & 53 & 146.83 & 24.148 & 3.317 & 98 & $.012 *$ & 2.576 \\
\hline$* p<05$
\end{tabular}

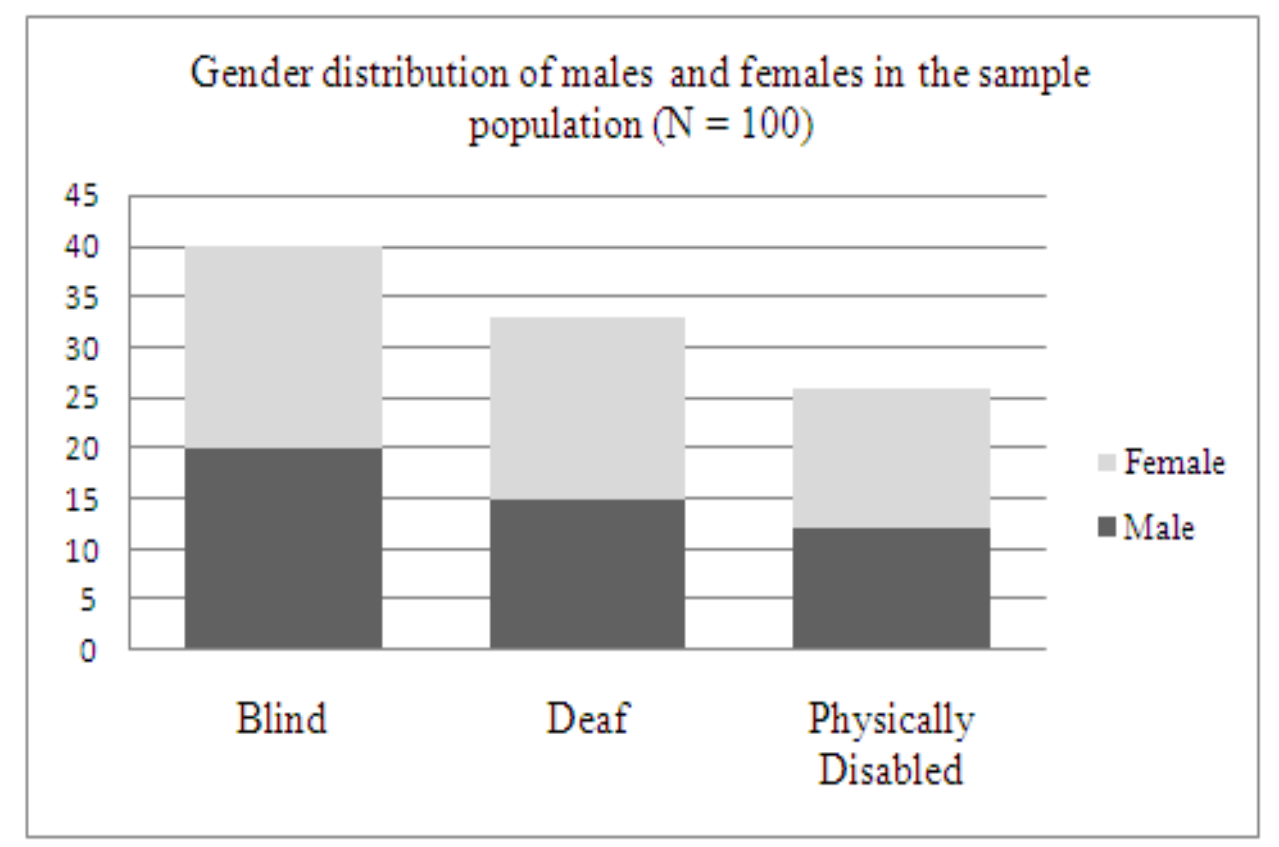

Figure 1. Stacked column chart showing the gender distribution of blind, deaf, and physically disabled adolescents 


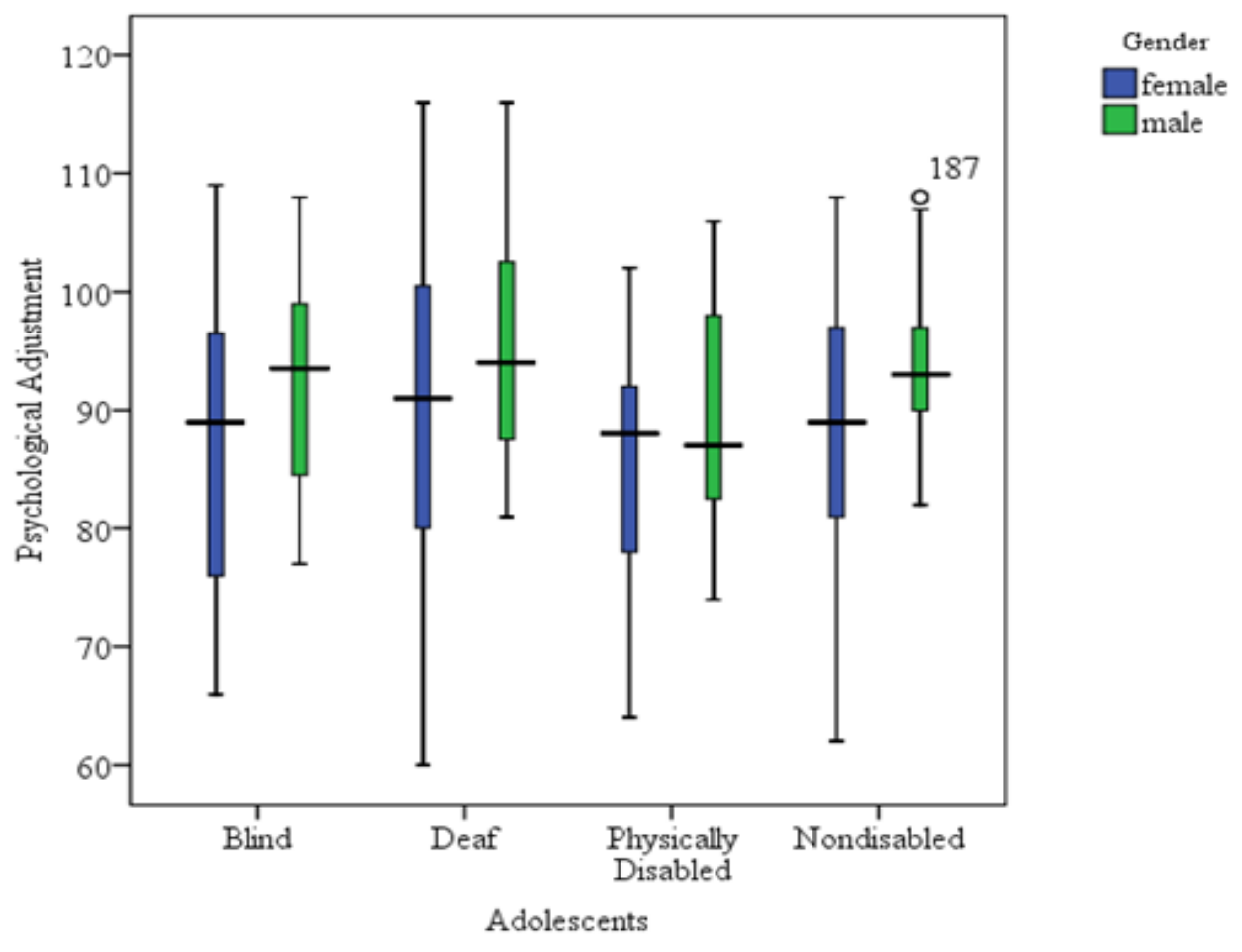

Figure 2. Clustered box plot showing psychological adjustment among blind, deaf and physically disabled male and female adolescent groups.

\section{Discussions}

Gender issues, especially gender discrimination are brought under the spotlight while putting forth the assumption that disabled male adolescents will show greater levels of psychological adjustment as compared to disabled female adolescents. The results show significant support for the hypothesis $[\mathrm{t}(98)=2.576, p<.05(.012)]$ following the trends of earlier researches (Ayubia, 1986, Ahmed, 2003, Holmbeck et. al., 2010). The results for this study with regard to gender differences can be understood under the umbrella of the predominantly patriarchal society of Pakistan, with a high Masculine dimensionality where many women are confined to their homes and movement outside the home or indulgence in activities that may grant them social freedom, is frowned upon or considered undesirable (Hofstede, 2001 \& Hofstede, Hofstede \& Minkov, 2010). Feminine attributes are understood as crippling with regard to their being able to assert or to take care of themselves (Qadir, Khan, Medhin \& Prince, 2011). This factor gains precedence in the case of female disabled adolescents who are perceived as weak by society.

During the interviews it was found that apart from those disabled females currently studying in schools, generally disabled females were given lower preference in continuing their studies or were kept illiterate while males were illiterate or could not continue their studies only due to extremely low socioeconomic status. Disabled boys were often enrolled in vocational training centres and parents were more concerned about their future skill status as breadwinners of the family.
While this created pressure on the disabled male adolescents, it was seen that it also provided them with an environment both inside and outside their homes where they were allowed to showcase their abilities, bring back earnings and consequently increase their feelings of self worth resulting in better adjustment patterns.

Most females were found to be leading a severely restricted life bound by cultural norms and traditions especially in the more conservative households. The results of a report by UNICEF (2003) mirror this pattern as it is seen that the girl receives poorer quality nutrition, health care and attention which may later affect the life expectancy. While a few seemed to be content with their lot, having adjusted to the 'protection' this lifestyle seemed to provide them, many openly regretted the loss or lack of their movement.

As the data for the research was collected using an interview format, several issues came to light while speaking to adolescents with disabilities and in some cases their families or their teachers. Security issues were a major concern for the parents of the female adolescents who were more confident about disabled males being able to take care of themselves outside the homes as compared to disabled females. The issue of restriction and disability thus emerges as a double edged sword providing a safety net within the confines of the home environment on one end and an increase in frustration levels lowering self esteem and feelings of competence on the other. Individual differences still arise as the researcher discovered in an encounter with two blind females in the hospital setting who were allowed to step out of their homes only to visit the hospital; a privilege 
ironically not available to their sighted sisters. In these isolated cases, their disability had become an unexpected source of freedom for them. Nevertheless it is a cause for concern that socio-cultural trends in gender disparity have not changed over the decades in the case of disabled individuals. Resultantly, disabled female adolescents show lower levels of psychological adjustment as compared to disabled males. This posits important questions related to the clinical implications for disabled females and their later adjustment patterns in marriage and motherhood. Zaidi, Mohsin and Saeed (2013) discovered strong support for adult physically disabled females to be diagnosed with anxiety and depression as compared to adult physically disabled males.

The results and the discussion for the variable of gender in disability emerge with indications of gender inequality led by security concerns for girls with disabilities as compared to boys with disabilities as seen through the lens of a typical collectivistic and masculine environment. The dynamics of this setup are far too complex to be covered by this research alone, however further researches using similar variables could help in creating awareness for equalization of opportunities available for disabled males as well as females.

\section{Conclusions}

Global trends, research evidence in Pakistan and the implications of this study point towards a greater need for understanding the needs of female disabled adolescents in order to build a cohesive society. Caregiver attitudes notwithstanding, it is the female adolescent's own perception that may create attitudes of self pity as she makes sense of her own self worth and this may in the end lower her self esteem. Adolescence is the best time period to introduce interventions on a clinical as well as educational level targeting the adjustment and coping strategies of disabled female adolescents.

\section{Limitations}

The sample size poses one of the major constraints of the study; however the nature of the study and the ground realities encountered during the intensive interviewing process made it difficult to gather a larger sample. In context of the sample size, the inclusion - exclusion criteria has been applied stringently and while this increases the validity of the results, a hitch is encountered in the reduction in generalization of the results to include all disabled adolescents.

This study has utilized traditional methods of psychological testing due to the unavailability of psychological tests for any of the variables made in Braille or Pakistan Sign Language. This is singularly unfortunate as several participants from the deaf adolescent population had to be excluded from the study on account of their difficulty with the written material.

\section{Recommendations}

A cross sectional research design across different strata of age related subgroups with different disabilities is suggested that would help in identifying age related patterns and differences. This is imperative for the formulation of adjustment based variations and clinical interventions.

The far reaching effects of changes in the nature of gender and other demographic information variables would also have to be considered in a longitudinal research plan. As Lee and Rojewski (2013) discovered, in a longitudinal multidimensional study of 585 individuals, mainly gender and socio economic status from among the factors of self concept, locus of control and mathematics achievement created the high aspiration or low aspiration divide in learning disabled or emotional-behavioural disorder groups in the long term.

\section{REFERENCES}

[1] Ahmed, B. (2003). Self esteem of physically disabled students. Unpublished thesis. Department of Psychology. Government College University. Lahore, Pakistan.

[2] Ayubia (1986). Handicapped children and their social adjustment. (Unpublished thesis). Department of Psychology. Government College University. Lahore, Pakistan.

[3] Bano, H. \& Hameed, A. (2011). Activities of physical education for girls with visual impairment and their access in Pakistan. Pakistan Journal of Special Education, 12, 11-19.

[4] Cohen, L. (1998). No Aging in India. Alzheimer's, the Bad Family, and Other Modern Things. Berkeley: University of California Press.

[5] Das, V. \& Addlakha, R. (2001/2007) Disability and domestic citizenship: voice, gender, and the making of the subject. Public Culture, 13(3), 511-531. Reprinted in B Ingstad \& SR Whyte (Eds) (2007). Disability in Local and Global Worlds, 128-148. Berkeley: University of California Press.

[6] Haber, A., \& Runyon, R.P. (1984). Psychology of Adjustment. Dorsey Press, Homewood, IL

[7] Hofstede, G. (1991). Cultures and Organizations: Software of the Mind. London: McGraw-Hill U.K.

[8] Hofstede, G. (2001). Culture's Consequences: Comparing Values, Behaviors, Institutions and Organizations across Nations. Thousand Oaks CA: Sage.

[9] Hofstede, G., Hofstede, G.J. \& Minkov, M. (2010). Cultures and Organizations: Software of the Mind. Revised and Expanded. 3rd edition. New York: McGraw-Hill U.S.A.

[10] Holmbeck, G.N., DeLucia, C., Essner, B., Kelly, L., Zebracki, K., Friedman, D., \& Jandasek, B.. (2010). Trajectories of psychosocial adjustment in adolescents with spina bifida: a 6-year, four-wave longitudinal follow-up. Journal of Consulting and Clinical Psychology, 78(4), 511-525. doi: 10.1037/a0019599.

[11] Itteyerah, M. \& Kumar, N. (2007). The actual and ideal 
self-concept in disabled children, adolescents and adults. Psychology and Developing Societies, 19 (1), 81-112.

[12] Kazmi, M. (2001). Subjective well being of disabled children. (Unpublished thesis). Department of Psychology. Government College University. Lahore, Pakistan.

[13] Khan, Q. (2008). Gender differences in self concept among adolescents with low vision. (An unpublished thesis in partial fulfillment of the requirements of M.S.E, Department of Special Education). University of Karachi.

[14] Lee, H. \& Rojewski, J. W. (2013). Brief report: A growth mixture model of occupational aspirations of individuals with high-incidence disabilities. Journal of Adolescence, 36(1), 233-239. doi: 10.1016/j.adolescence.2012.11.003.

[15] Mehta, V. (1984). Daddyji - Mamaji. London: Picador. 121-131.

[16] Mirza, N. (1994). Etiological factors responsible for the maladjusted student. Unpublished thesis. Department of Psychology. Government College University. Lahore, Pakistan.

[17] Nancoo, L. (2011). Marriage-able? Cultural Perspectives of Women with Disabilities of South Asian Origin. Essays on the topic of Women and Disability: South - East Asian Women, Disabilities, 10.

[18] Qadir, F., Khan. M.M., Medhin, G., \& Prince, M. (2011). Male gender preference, female gender disadvantage as risk factors for psychological morbidity in Pakistani women of childbearing age - a life course perspective. BMC Public Health, 11. doi:10.1186/1471-2458-11-745.
[19] Sabir, F. (1999). Academic self concept and achievement among university students as related to their psychological adjustment. Published research monograph, NIP, Quaid e Azam University, Islamabad, Pakistan.

[20] Schillmeier, M. (2008). (Visual) Disability - from exclusive perspectives to inclusive differences. Disability \& Society, 23 (6), 611-623. doi: 10.1080/09687590802328493.

[21] Shaffer, A., Yates, T., \& Egeland, B.R. (2009). The Relation of Emotional Maltreatment to Early Adolescent Competence: Developmental Processes in a Prospective Study. Child Abuse \& Neglect: The International Journal, 33(1), 36-44.

[22] Thomas, T.M. \& Singh, N. (2006). Social maturity profile of persons with multiple disabilities: A comparative analysis. Disabilities and Impairments, 20(1), 21-27.

[23] Turner, R.J. \& McLean, P.D. (1989). Physical disability and Psychological distress. Rehabilitation Psychology, 34(4), 225-242.

[24] UNICEF, (2003). Examples of Inclusive Education. Pakistan. Retrieved from http://unesco.org.pk/education/icfe/resources/res26.pdf.

[25] World Health Organization (1980). International Classification of Impairments, Disabilities and Handicaps. Geneva, Switzerland: WHO.

[26] Zaidi, I.H., Mohsin, M.N., \& Saeed, W. (2013). Relationship between alexithymia and locus of control among graduation students: a case study from Faisalabad. International Journal of Environment, Ecology, Family and Urban Studies, 3(1) 